\title{
Internalized Misogyny and Ambivalent Sexism in the Movie Kabir Singh
}

\author{
Poonam \\ Department of English and Foreign Languages, SRM Institute of Science and \\ Technology, Kattankulathur Campus, Chengalpettu, Tamilnadu, India
}

\begin{abstract}
The movie Kabir Singh, which was released in the second decade of 21st century is the epitome of misogyny and ambivalent sexism. The depiction of encapsulation of sexism is quite real but the positive undertone of conflicted sexism makes the story repugnant. In this research paper, researcher has tried to find out the depth of misogyny in Indian society and how hostile and benevolent sexism is abating the identity of women. In order to understand the nuances of gender - based prejudices, researcher has used social psychologists, Peter Glick and Susan Fiske's idea of sexism of the late 1990s, on the movie Kabir Singh. This movie was first released as "Arjun Reddy" in the southern part of India and its tremendous success and box office collection led it's remake for the northern side of India by the name "Kabir Singh" with famous face of Shahid Kapoor to attract the audience. In the movie the audience are taken in to the college romance and are manipulated to admire the blatant objectification and to perceive the subsequent actions of the main lead as romantic and caring while being strong and masculine.
\end{abstract}

KEY WORDS: AMBIVALENT SEXISM, HOSTILE SEXISM, BENEVOLENT SEXISM, GENDER EQUALITY, GENDER ROLE.

\section{INTRODUCTION}

Glick and Fiske have examined the attitude on sexism in a more nuanced way, looking at the possibility of complex sexist attitude that may entail both positive and negative attitude towards women. Ambivalent sexism can be understood by examining its component which are paternal and caring attitudes, or benevolent sexism, and aggressive and mistrusting attitudes or hostile sexism. In the movie Kabir Singh the single-minded conquest of the male lead Kabir Singh on a much younger new student, the pretty Priti Sikka brings the questionable space of 'putting a stamp of ownership' and audience are taken aback by the complete submissiveness of the mouse-like girl in question. Female lead of the movie, Priti Sikka, is the victim of both kind of sexism which audience identified as concern of father and passionate love of Kabir Singh. For Priti, where to sit, where to stay is decided by Kabir in the college and whom to marry is decided by her father giving her no right over her life

Biosc Biotech Res Comm P-ISSN: 0974-6455 E-ISSN: 2321-4007

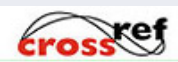

Identifiers and Pagination

Year: 2021 Vol: 14 No (8) Special Issue

Pages: $44-48$

This is an open access article under Creative

Commons License Attribn 4.0 Intl (CC-BY).

DOI: $h t t p: / / d x$.doi.org/10.21786/bbrc/14.8.10 whatsoever. The notion of men being intrinsically superior to women is found to be ubiquitous in the movie and this prejudice is not questioned by Priti who is an extremely talented medical student and an independent woman. Conventionally hostile sexism is diagnosed effortlessly, it is benevolent sexism which is unobtrusive.

In addition to the sexist attitudes individual confronts externally on a day-to-day basis, these beliefs can be internalized. According to Spengler (2014), internalized misogyny is made up of two main elements: selfobjectification and passive acceptance of gender roles. The outcome of these components are contravening leading to myriad of problems like psychological distress, disordered eating, and mental illness. The nature of misogynistic and sexist messages which are hurled upon women by patriarchal society is so pervasive that the internalization of sexist ideology becomes inconspicuous. Almost all the abusive words is directed towards degrading a women as women were always seen as a commodity rather than as an individual. So if a man has to be abused, the derogatory words are used for the women of his house not for him. This illustrates how extensive internalized sexism truly is within society.

Internalized Misogyny: Self-Objectification is one of the integral part of internalized misogyny. It leads to self-scrutiny as people view themselves as objects for 
use instead of as human being. Women face existential crisis if they get this feeling that they are not useful anymore which results in worshipping sacrificial women who prioritize others over themselves. The other widely accepted norms in internalized misogyny is passive acceptance of gender role. If a man is being rude and abusive in the family he gets excused claiming that he would have had a rough day in the workplace. Whereas a women is expected to take care of the household and family members and treat her career as a perk given with this assurance that she won't neglect her duties towards her house. The gender role is never questioned in the premises as it has been internalized from the generations.

A culture which promotes the virginity and chastity of women will always question her sexual choices. If a man has multiple sexual partners he is awarded with the adjectives of being a cool dude, somebody to look forward to but if a woman has multiple sexual partners she is degraded with the adjectives of being slut, whore etc, somebody to frown upon. Same action leads to different consequences as it is performed by different gender and is widely accepted. Negative stereotype is another outcome of internalized misogyny which makes us believe that if it is women she would be weak in math or she must be a good cook and apt to take care of all other household chores and incapable of performing outdoor task. The capability of many women gets smothered with this vacuum of negative stereotype which stops them to show their potential in varied fields as it confines them within the four walls.

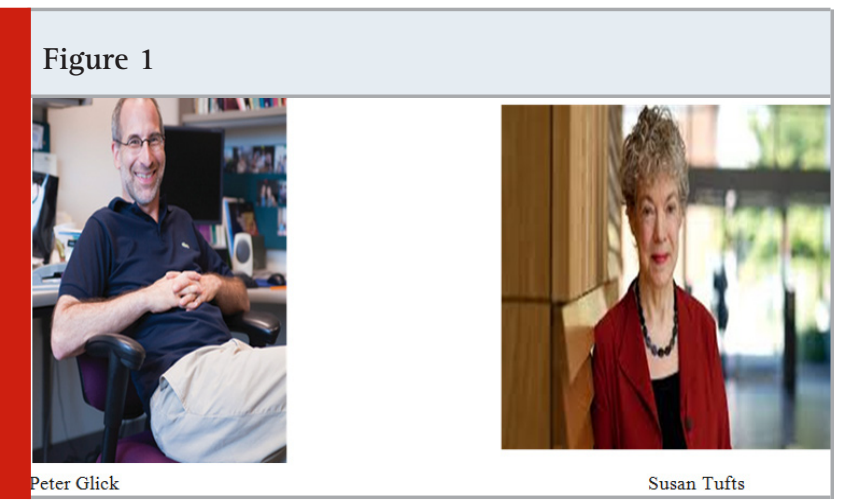

Ambivalent Sexism: Sexism is defined as a belief, practice, or system that supports the notion that men are intrinsically superior to women. Dr. Peter Glick is the Henry Merritt Wriston professor in the social sciences at Lawrence University and senior scientist with the Neuroleadership institute. His award winning scholarship includes groundbreaking theories of stereotype content, ambivalent sexism, and toxic organizational culture. Susan Tufts is the Eugene Higgins professor of Psychology and Public affairs in the department of Psychology at Princeton University. Being a social psychologist she is known for her work on social cognition, stereotypes, and prejudice. Her theoretical contributions include the development of the stereotype content model, ambivalent sexism theory, power as control theory, and the continuum model of impression formation. Her theoretical contributions include the development of the stereotype content model, ambivalent sexism theory, power as control theory, and the continuum model of impression formation.

Together they came up with the Ambivalent sexism theory, which revolutionized how scholars understand sexism by distinguishing benevolent sexism (a term coined by them) from hostile sexism. Benevolent sexism promotes the thought that women are wonderful, but weak and dependent upon men. This kind of perspective restrict women to show their full potential by restricting them from any challenging assignment, depriving them of honest feedback and autonomy. Research across 25 nations proves that benevolent sexism predicts actual gender inequality which is evident by fewer women in powerful position in the work place. Hostile sexism aims to validate “.....male power, traditional gender roles, and men's exploitation of women as sexual objects through derogatory characterizations of women" (Anderson, 2010, pg 151). This sexism is furthermore open about misogyny than benevolent sexism. A hostile sexism believes that women are manipulative,

violent and endeavor to control men through seduction. Gender equality is often seen as an attack on masculinity or traditional values in the eyes of hostile sexism. It often seeks to suppress the movements of feminism. Some women attune themselves to the gender norms by respecting and capitulating to patriarchy and they are acknowledged as pure, innocent and gentle. But on the other hand, there are women who refuse to comply with established gender role and hence they are identified as manipulative, violent and controlling. The notion of accepting a women the way she is never brought in to consideration. While hostile sexism predicts violence against women, benevolent sexism tends to predict victim blaming in the context of that violence.

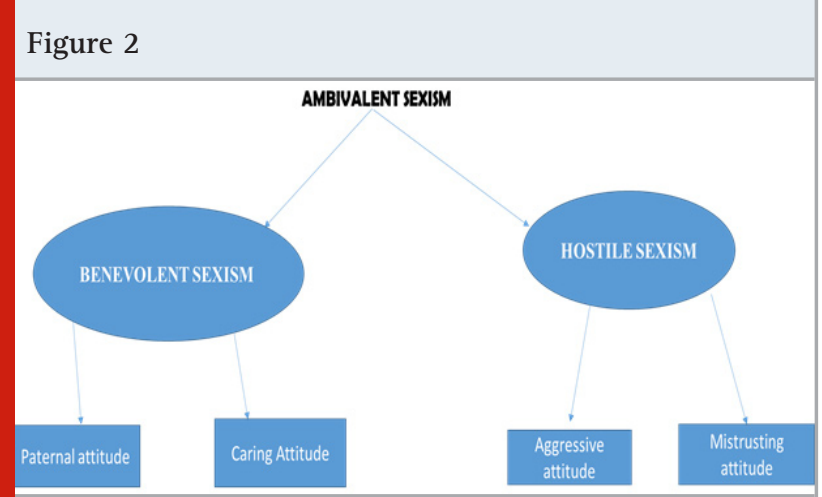

Kabir Singh: Films are rarely neutral in their depiction of anything. In Kabir Singh, they have depicted misogyny that is real (that is not the problem), but with a positive undertone (this is the problem). About 25 minutes into the film, Kabir (Shahid Kapoor) sees his love interest Preeti (Kiara Advani) for the first time. A romantic background creates an environment that allows the audience to admire this blatant objectification. It guides the audience 
towards perceiving his subsequent actions as romantic and caring while being "strong" and masculine.

The way movie Kabir Singh has normalized the internalized misogyny and ambivalent sexism for its audience is unconscionable. The audience tend to imitate the character which they see in the movies and if the movie is a blockbuster, it impacts much wider viewers. The female lead of the movie, Priti Sikka, although an educated girl is showed to be meek who doesn't even retaliate when Kabir Singh gives a peck on her cheek without her consent stating that "it's okay, nobody saw". Throughout the movie she is showed to accept the dominance of Kabir Singh without even realizing the master - slave relationship in which she was in. The movie was criticized for the male lead being abusive, alcoholic and violent but no critic has paid attention to what the female lead had to go through. The researcher has mentioned few scenes from the movie below which shouts ambivalent sexism and internalized sexism out loud.

Figure 3

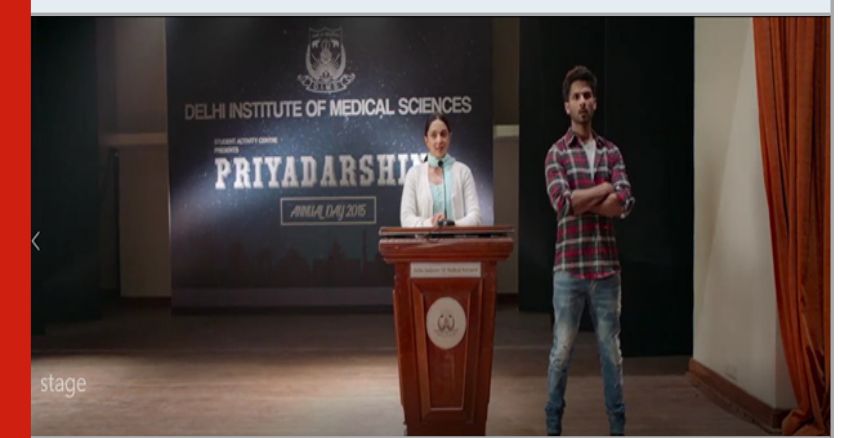

This scene screams benevolent sexism apart from other hypocrisies. Priti Sikka is showed in need of Kabir Singh even to deliver her speech. The latter doesn't hesitate to stand on the stage to ensure that the crowd remains silent and listen to his lady love not because she has something significant to say but because there will be consequences if the crowd doesn't oblige to the dominance of Kabir Singh. The friends (male) are among the crowd too and is trying calm down the crowd and pay attention to what Priti had to say. Likewise in most of the fairy tale girls are projected as a damsel in distress who need their knight in shining armor to rescue them from the intractable situation.

Glorification of such scenes greatly impacts the younger women who starts contemplating the presence of such male in their life making them believe that they are not self-sufficient. Instead of protecting, women should be encouraged to face adverse situation and come out victorious by themselves realizing their potential instead of being dependent on others. The hostile sexism of crowd is noticeable as they believe that if a woman is up there on the stage, the crowd shouldn't be listening to her as it would be against their masculinity to listen to a lady which might later motivate her to be the leader. It also results in Hypermasculinity which is a gender-based ideology of exaggerated beliefs about what it is to be a 'man'. These traditional tropes of masculinity promote the idea that men should be authoritative, emotionally bankrupt, and the breadwinner of the family. Internalized misogyny cannot be ignored here which sways the crowd with negative stereotype that a girl would only speak about melodrama rather that something relevant and intellectually enlightening.

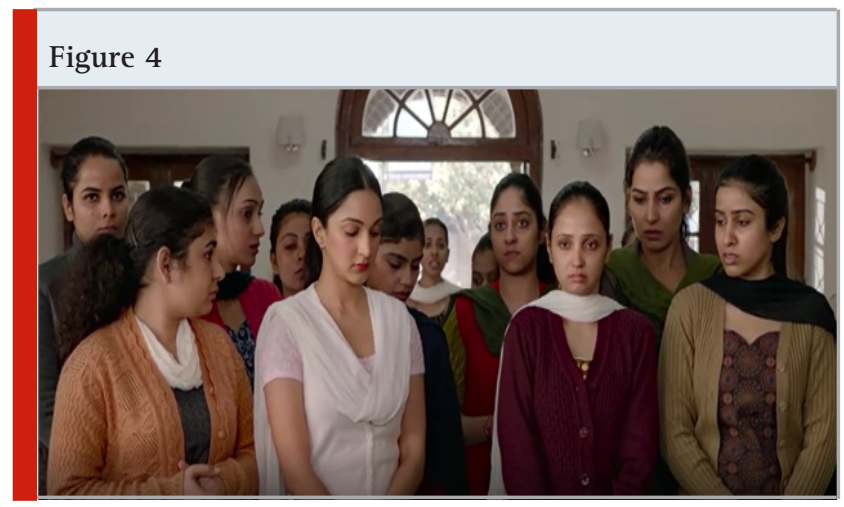

The scene in which Priti is rescued from ragging under the influence of none other than Kabir Singh's supremacy urges the men to come out from their hero complex and let women deal with their combat. Here if Priti had gone through the ragging she would have ended making friends but the interference of Kabir secluded her seizing her potential altogether. Benevolent sexism, instead of being overtly misogynistic, are often characterized by a desire to protect and preserve women. In many culture and situation these attitude are referred as chivalry or traditional values but in the long run, despite of seemingly positive characteristics it becomes dangerous and damaging to women's rights and even their safety.

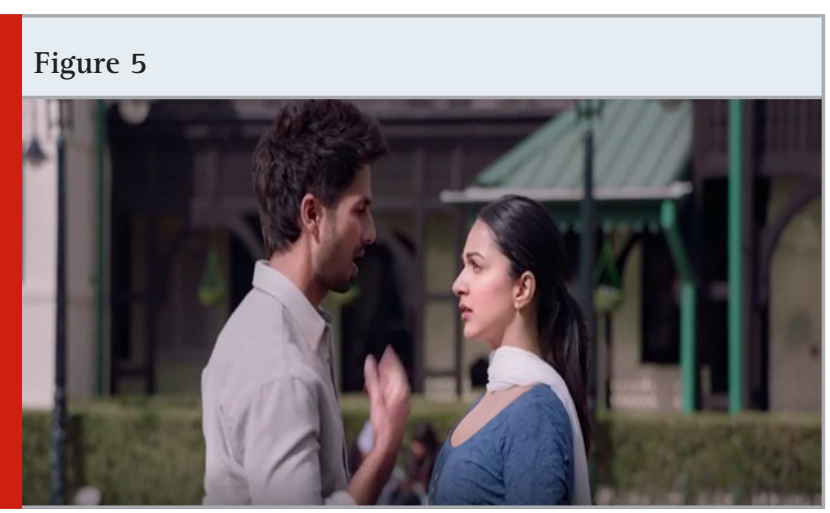

As benevolent sexism advocates in protecting women it also criticizes women taking their own decision. In the above scene when Priti takes her decision to come and meet Kabir in Shimla where he has gone for higher studies, she faces criticism instead of a welcome. When she asks Kabir to kiss her, he states that the public display of affection is scrutinized in the present campus. The gesture which is questionable here has been performed earlier when Kabir had kissed Priti in Delhi campus without her consent with complete authority and when the same authority is asked by Priti she is brutally denied even though they are in love with each other and are 
consensual. Here, hostile sexism also comes in the picture which makes Kabir feel that may be Priti would get upper hand in the relationship by manipulating him.

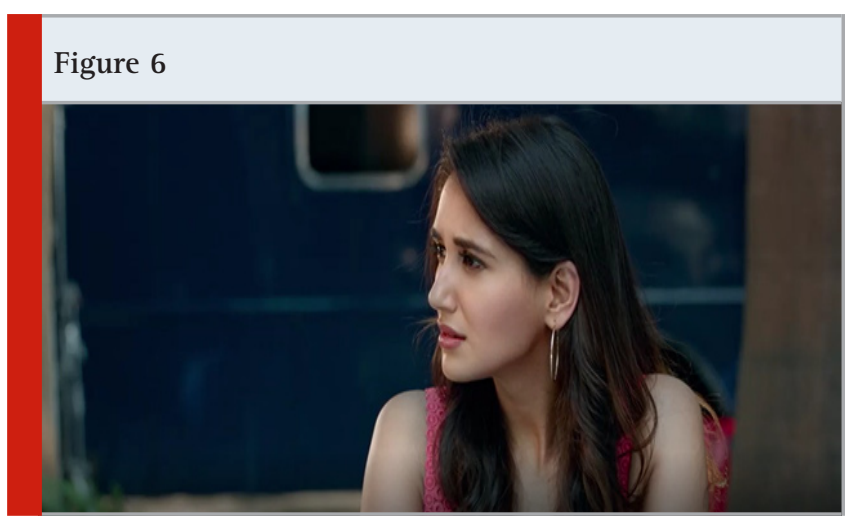

Hostile sexism is more openly misogynistic than benevolent sexism. It tends to look at the women as manipulative, angry, and seeking to control men through seduction. In the above scene, the girl is a film actor who openly admits she likes Kabir. Her openness is misinterpreted and Kabir offers her to be in a sexual relationship without any commitment. If a man shows his inclination towards a women that gesture is usually taken with dignity and long term commitment is offered but the same gesture is taken in a negative sense when it is initiated by a woman. Hostile sexism often views gender equality as an attack on masculinity or traditional values. A women is generally expected to be coy and wait for the first move rather than making one and if one does she is slut shamed.

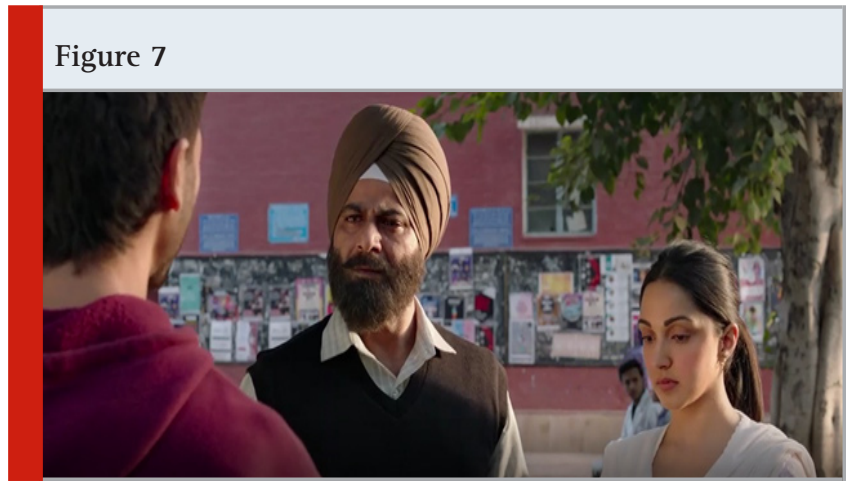

This is the scene where father of Priti is looking for Kabir as he is the son of an acquainted person and is senior. The purpose is to find a savior for her daughter within the campus. At home she was protected by her father and outside the house also father is making sure of her guardianship. The girl who has achieved academic success is considered to be so naïve that she won't be able survive on her own without the support of a man. Even if this is true then let her learn from her struggles and become an independent women. Constant protection hinders the potential of women making her handicapped and dependent throughout the life.

Throughout the movie, one thing stands out-Kabir Singh's anger. In the beginning of the film, he says
"I'm not a rebel without a cause". However, the director doesn't deem explaining this cause important enough. Kabir Singh has everything, supportive parents, lovely grandmother, understanding brother, amazing friends and even a submissive girlfriend, and yet he is angry. The movie gives no reasonable explanation for such anger but thoroughly justifies it. It seems that just because Kabir is a man, he can afford to be rude to his parents, his patients, his staff, and his friends and suffer no consequence. He announces to a classroom full of boys that they're not allowed to interact with this girl. He barges into the girl's classroom, asks Priti to sit in the front row and decides who she should be friends with so she can "perform better academically". He starts entering her classroom and taking her away to "private tuitions" on a field.

While Preeti is showed to be admiring these actions in the film, the trauma any woman would go through if faced by such blatant harassment in real life is unimaginable. In a world where raising men and women differently has become normalized in every echelon of society, it's disappointing to see experienced professionals celebrate misogyny and harassment. Glorifying such actions only encourages others to imitate this behavior. The movie Kabir Singh is filled with such stigma be it when Priti is slapped hard by her own mother when she openly describes the number of times she had sex with Kabir or Priti being dragged out of the class to get privately tutored by Kabir or being asked by him to wear her stole properly. After Preeti gets a "deep" cut on her foot 45 minutes into the film, Kabir decides she must move into his dorm so he can help her study. Kabir makes countless decisions on her behalf that are shown to have a positive impact on both their academic and personal lives. The movie constantly shows that a responsible, "Masculine" man makes the important decisions for his female partner and protect her from any harm, even if that means stripping her of her agency to consent. The incidents are endless but the way these gestures has been internalized in the current patriarchal society is dangerous. The impact it has is precarious for the present generation as well as future generation of women.

\section{CONCLUSION}

The impact of these sexist behavior is unrepairable. In Benevolent sexism, women are seen as fragile and as someone who needs protection which leads to the belief that they are weaker sex and are inferior to men. It becomes unbearable for a men with such belief to accept a women in leadership position. They firmly believe that the place of women is in home and their identity is only as a care giver. Men don't even bother to know the interest of women and their potential because of which the talent of the latter is succumbed to death within the four walls. Hostile sexism wounds women in a different manner. This kind of belief accepts and perpetrate violence and accuses women's outspokenness for the sexual violence and rape. Women are believed to be manipulative and threat to masculinity. The movie Kabir Singh advertises every aspect of the above mentioned 
sexism and its box office success gives a horrendous picture of the society who believes and accepts such kind of sexist behavior. Despite of strong technical element in the movie, it was impossible not to cringe at the repetitive misogyny, glorification of masculine stereotypes, and lack of consent depicted in the lead relationship.

Heterosexual men are almost always the protagonists of films. They are depicted as 'protectors' of women, macho, easily angered and irritable, independent thinkers and decision makers whereas the women are generally ancillary characters who are domestic divas or sex objects of the film. They are irrationally emotional, physically weak and reliant on their male partners. The movie Kabir singh is no different. Instead of showing Kabir checking into rehab and getting his anger issues, drug and alcohol addictions, and numerous other flaws into control, it is showed how love is supposed to accept it all. How "true love', which here is a toxic relationship, is supposed to bear all the abuse and still survive. The movie shows how Kabir can be ungrateful, vengeful, violent, misogynist, patriarchal, and yet the woman he loves would accept him. It is a typical Bollywood story of the abused falling in love with the abuser. Director of the movie Sandeep Reddy Vanga in his interview has said that it's not love without passion but what he ended up making is sexist love rather than passionate love. It is time for the movie makers to recognize the mass appeal of the movies they make and be sensible towards the society rather than on box office collection.

\section{REFERENCES}

Anderson, K. J. (2010). Benign bigotry: The psychology of subtle prejudice. New York, NY: Cambridge University Press.

Becker, J. C., \&t Wright, S. C. (2011). Yet another dark side of chivalry: Benevolent sexism undermines and hostile sexism motivates collective action for social change. Journal of Personality and Social Psychology,
101(1), 62-77.

Begany, J. J., \&t Milburn, M. A. (2002). Psychological predictors of sexual harassment: Authoritarianism, hostile sexism, and rape myths. Psychology of Men $\mathrm{Ct}$ Masculinity, 3, 119-126.

Dardenne, B., Dumont, M., \&t Bollier, T. (2007). Insidious dangers of benevolent sexism: Consequences for women's performance. Journal of Personality and Social Psychology, 93, 764-779. doi:10.1037/00223514.93.5.764

Glick, P., \& Fiske, S. T. (1996). The Ambivalent Sexism Inventory: Differentiating hostile and benevolent sexism. Journal of Personality and Social Psychology, 70, 491-512.

Glick, P., \& Fiske, S. T. (1999). The ambivalence toward men inventory: Differentiating hostile and benevolent beliefs about men. Psychology of Women Quarterly, 23, 519-536.

Glick, P., \& Fiske, S. T. (2001). An ambivalent alliance: Hostile and benevolent sexism as complementary justifications of gender inequality. American Psychologist, 56, 109-118.

Glick, P., Fiske, S. T., Mladinic, A., Saiz, J. L., Abrams, D.,Masser, B., . . . López López, W. (2000). Beyond prejudice as simple antipathy: Hostile and benevolent sexism across cultures. Journal of Personality and Social Psychology, 79, 763-775

https://www.youtube.com/watch?v=MIRLo6kpuHI Interview of Sandeep Reddy Vanga with Anupama Chopra

Lee, T. L., Fiske, S. T., Glick, P., \&t Chen, Z. (2010). Ambivalent sexism in close relationships: (Hostile) power and (benevolent) romance shape relationship ideals. Sex Roles, 62, 583-601. https://doi.org/10.1007/ s11199-010-9770-x

Vanga, Reddy Sandeep, Kabir Singh, Netflix India. 